\title{
Paddlefish as Potential Acoustic Targets for Abundance Estimates
}

\author{
R. Scott Hale* \\ Ohio Department of Natural Resources, Division of Wildlife, \\ 10517 Canal Road Southeast, Hebron, Ohio 43025, USA \\ JOHN K. HORNE \\ University of Washington, School of Aquatic and Fishery Sciences, \\ Box 355020, Seattle, Washington 98198-5020, USA \\ Donald J. Degan \\ Aquacoustics, Inc., \\ 29824 Birdie Haven Court, Sterling, Alaska 99672-1473, USA

\section{Elizabeth Conners} \\ National Marine Fisheries Service, Alaska Fishery Science Center, \\ 7600 Sand Point Way Northeast, Seattle, Washington 98115-6349, USA
}

\begin{abstract}
Underwater acoustics is a noninvasive sampling technique that potentially reduces expense and injury to target species, but this method may be underutilized for sampling large freshwater fishes. We measured target strength (TS), developed anatomically based backscatter models, and conducted gill-net and acoustic surveys of paddlefish Polyodon spathula to explore the potential use of acoustic surveys for estimating the abundance of large freshwater fishes. Mean TS measured from two size-groups of paddlefish at $200 \mathrm{kHz}$ was -37.14 decibels $(\mathrm{dB}$; $\mathrm{SD}=$ -2.36) for age-0 fish (353-406 $\mathrm{mm})$ and $-27.25 \mathrm{~dB}(\mathrm{SD}=-2.21)$ for adult fish $(1,018-1,284$ $\mathrm{mm}$ ), indicating that TS could differentiate these size-groups. Backscatter models identified strong contributions of the swim bladder to TS and revealed the sensitivity of acoustic backscatter to paddlefish length, aspect, and acoustic carrier frequency. Model results were generally within one $\mathrm{SD}$ of measured means from individual fish of each size-group. Target strength results were used to count two populations of adult paddlefish in mobile surveys using an echo sounder with a 200$\mathrm{kHz}, 6^{\circ}$ split-beam transducer. One population was stocked in 1.6-ha Hebron Pond, where no large fish were previously present. The other population resided in 28-ha Horseshoe Lake, an Ohio River backwater. Twenty-one paddlefish stocked in Hebron Pond were accurately counted during the first of six side-looking surveys, but subsequent surveys only counted between two and seven fish. Depletion gillnetting results in Horseshoe Lake provided an estimated baseline of $130 \pm 55$ paddlefish for comparison with abundance estimates from side-looking and down-looking acoustic surveys during day and night. Acoustic abundance estimates ranged from 187-313 fish (sidelooking) to 3,464-13,489 fish (down-looking) depending on survey time (day or night) and the approach to analysis. Ratio estimates and cluster estimates provided similar results, and the coefficient of variation of the mean (100.SE/mean) ranged from $20 \%$ to $50 \%$. Acoustic estimates were either greater or more variable than those derived from depletion gillnetting, yet acoustic surveys required only 6 man-hours compared to 180 man-hours for the gillnetting estimate. Our study is the first to indicate that TS can be used to count adult paddlefish and that, upon refinement of survey techniques, TS can be used to estimate paddlefish abundance. The benefits of acoustic surveys may be realized sampling other large freshwater fishes when the target species can be differentiated with TS and considerations are made for transducer selection.
\end{abstract}

Acoustics may improve assessment of large freshwater fishes if acoustic target strength (TS) can be used to accurately identify and count large fish in surveys. Further, acoustic surveys can determine distribution of large fishes, providing ad-

\footnotetext{
* Corresponding author: scott.hale@dnr.state.oh.us

Received April 8, 2002; accepted January 9, 2003
}

ditional insight into their ecology. Within North America, published acoustic studies of freshwater fishes appear dominated by assessment of small pelagic fishes (Burczynski et al. 1987; Brandt et al. 1991; Degan and Wilson 1995; Schael et al. 1995; Fleischer et al. 1997; Warner et al. 2002) or salmonids (Thorne 1983; Mulligan and Kieser 1986; Parkinson 1994; Beauchamp et al. 1997; Yule 2000), with few results reported for larger 
freshwater fishes common to inland rivers, lakes, or reservoirs. This may be the result of limited TS data for larger fishes or a lack of information regarding how equipment factors or the biology of large fishes influence TS.

Target strength is derived from the logarithm of backscattering cross section $\left(\sigma_{\mathrm{bs}}\right)$, or acoustic reflectivity from a fish, and is strongly influenced by biological factors and transducer frequency. Fish length, fish behavior, and the presence of a swim bladder are major biological factors influencing amplitude of acoustic backscatter, whereas TS generally increases with sonar carrier frequency and fish size (MacLennan and Simmonds 1992; Horne and Clay 1998). The relations between biological and equipment factors provide insight regarding TS, equipment selection, and use of acoustic survey data.

Differentiation of fish size by TS is complex because the swim bladder is the primary source of acoustic backscatter in most fishes, and the swim bladder's size, position, and angle in relation to the transducer influence TS at any frequency (MacLennan and Simmonds 1992; Brandt 1996). Generalized equations to estimate fish lengths from TS have been developed for the side, dorsal, and any aspects (Love 1969, 1971, 1977). These equations are widely used, and have proven useful for a variety of species (Burczynski et al. 1987; Brandt et al. 1991; Yule 2000; Warner et al. 2002). However, the empirical, species-specific TS-length relations more closely estimate true fish size due to the complexity of acoustic backscatter (Foote 1987; MacLennan and Simmonds 1992; Fleischer et al. 1997). Empirical, species-specific TS-length relations may be particularly important for large fishes because TS becomes more sensitive to the swim bladder position within a fish and to the fish angle to transducer as fish length increases, especially at high frequencies (Clay and Horne 1994; Jech et al. 1995).

We initiated this study to determine the potential of acoustics to estimate the abundance of a large freshwater fish species. We sought to determine whether large fish could be identified via TS and, if so, whether abundance could be estimated from counts of large fish derived from acoustic surveys. We used the paddlefish Polyodon spathula as our study organism because paddlefish were readily available and among the largest fish in our region. Paddlefish are widely distributed throughout the Mississippi River basin and can attain lengths exceeding $2 \mathrm{~m}$ (Jennings and Zigler 2000). As is characteristic of other large fishes native to large rivers, paddlefish populations are difficult to quantify because they are very mobile and can be difficult to sample adequately. Estimation of paddlefish populations with mark-recapture methods is hindered by violations of methodological assumptions of both open and closed population models and by a lack of sufficient sample sizes (Runstrom et al. 2001), indicating a need for alternative methods of estimating abundance. In addition, interest in paddlefish has increased since its protection in 1994 through the Convention on International Trade in Endangered Species of Wild Fauna and Flora (Appendix II listed species) (Jennings and Zigler 2000). Specific objectives of this study were to (1) measure TS of known-length paddlefish, (2) develop anatomically based acoustic backscatter models for comparison with acoustic results, and (3) estimate paddlefish abundance. Although paddlefish are most frequently associated with large rivers and reservoirs, we conducted our study in smaller environments to ensure that populations were closed.

\section{Study Area}

Our study was conducted in a pond at the Hebron State Fish Hatchery, Hebron, Ohio, and at Horseshoe Lake, a small lake located along the southern Indiana-Ohio border. Hebron Pond is 1.6 ha, is roughly circular, has a maximum depth of 4 $\mathrm{m}$, and contained no large fish prior to paddlefish introduction. Horseshoe Lake is a 28 -ha excavated quarry near the Ohio River. It is steep sided, has a maximum depth of $13 \mathrm{~m}$, and is connected to the Great Miami River via a 40-m-wide inlet at a point $2 \mathrm{~km}$ upstream from the confluence of the Great Miami and Ohio rivers. Tagging studies indicate that Ohio River paddlefish move to and from Horseshoe Lake (Henley et al. 2001).

Hebron Pond and Horseshoe Lake were also used for abundance experiments. Hebron Pond provided a controlled environment that was easy to sample and had no additional large fish present that might be confused with paddlefish in our acoustic surveys. Horseshoe Lake was selected because paddlefish had been previously sampled there and because the lake inlet could be blocked with a net to contain paddlefish. Large fishes that might be confused with paddlefish in Horseshoe Lake acoustic surveys include bigmouth buffalo Ictiobus cyprinellus, smallmouth buffalo Ictiobus bubalus, black buffalo Ictiobus niger, common carp Cyprinus carpio, channel catfish Ictalurus punctatus, flathead catfish Pylodictis olivaris, and striped bass Morone saxatilis. 


\section{Methods}

Target strength measurements.-A $200-\mathrm{kHz}$ BioSonics DT 6000 echo sounder containing a $6^{\circ}$ (3-decibel $[\mathrm{dB}]$, half-power points) split-beam transducer with a source level of $214.1 \mathrm{~dB} / / \mu \mathrm{Pa}$ and receiver sensitivity of $-53 \mathrm{~dB} / \mu \mathrm{Pa}$ was used to collect acoustic data. Sample pulse duration was set at $0.4 \mathrm{msec}$, the pulse rate was set at 10 or 15 pings/s, and a threshold of $-57 \mathrm{~dB}$ was used to filter small targets. The system was calibrated at the BioSonics, Inc., facility in Seattle, Washington, and then field calibrated with a tungsten carbide reference sphere following the procedures recommended by Foote and MacLennan (1984).

Target strength was measured on tethered hatchery and wild paddlefish during October 4-6, 1999. Five-month-old paddlefish ranging in size from 353 to $406 \mathrm{~mm}$ standard length (SL) were obtained from the Kentucky State University Aquaculture Research Center, Frankfort, Kentucky. Wild fish ranging in size from 1,018 to $1,218 \mathrm{~mm}$ SL were collected from the Ohio River and Horseshoe Lake with gill nets. These fish were held in ponds at Hebron State Fish Hatchery until needed, whereas others were collected at Horseshoe Lake on October 5-6, 1999, and measured on-site.

In preparation for TS measurements, each fish was measured (SL) and anesthetized in a bath of $60 \mathrm{mg} / \mathrm{L}$ clove oil (Anderson et al. 1997). Anesthetized fish were placed in a gill-net sock and lowered to $10 \mathrm{~m}$ beneath the transducer by use of monofilament line and small weights at the dorsal aspect. We collected about 1,000-echo amplitude or TS measurements from each fish when the individual was near the center of the beam and movement was minimal. Target strengths were estimated with the equation TS $=10 \times \log _{10}\left(\sigma_{\mathrm{bs}}\right)$, where $\sigma_{\mathrm{bs}}$ is the backscattering cross section (i.e., the amplitude of echo returned from the fish). The null hypothesis that mean TS of age- 0 and adult paddlefish were equal was tested with a pooledvariance $t$-test (Snedecor and Cochran 1980) at an $\alpha$ value of 0.05 .

Acoustic backscatter modeling.-Acoustic backscatter was estimated via digitized dorsal and lateral radiographs and an anatomically based numeric model. Three age-0 (336-346 mm SL) and seven adult (894-1,277 mm SL), surface-adapted (swim bladder allowed to adjust to normal surface pressure) paddlefish were transported to the Ohio State University Equine and Bovine Veterinary Clinic for radiographing. Each fish was anesthetized as in tethering experiments, measured (SL), placed flat on white freezer paper for dorsal and lateral tracing, moved to an acrylic cradle, and then radiographed in dorsal and lateral aspect with a Picker International model VTX 1050 X-ray machine (settings: $51-100 \mathrm{kVp}$ [kilovotage peak], 20-50 mAs [milliamp seconds]). Dorsal and lateral radiographs were converted to digital data files by tracing silhouettes of bodies (not including fins) and swim bladders, scanning traces to graphics files, digitizing graphics files at 1-mm resolution, and scaling the images to their true sizes. The axis horizontal to the transducer face was defined from the tip of the snout to the middle of the caudal peduncle (Olsen 1977).

Backscatter amplitudes of the 10 paddlefish were estimated with a Kirchhoff-ray-mode (KRM) backscatter model (Clay and Horne 1994). In calculations of backscatter, the fish body is represented by a set of contiguous, fluid-filled cylinders surrounding a set of gas-filled cylinders representing the swim bladder. The KRM model computes complex backscattering lengths (Medwin and Clay 1997) separately for the swim bladder $\left(L_{\mathrm{sb}}\right)$ and fish body $\left(L_{\mathrm{fb}}\right)$. Coherent backscatter for the whole fish $\left(L_{\mathrm{wf}}\right)$ is assumed, and $L_{\mathrm{fb}}$ and $L_{\mathrm{sb}}$ sum as the complex function $L_{\mathrm{wf}}=L_{\mathrm{fb}}+L_{\mathrm{sb}}$. A nondimensional measure of echo amplitude derived from backscattering length divided by fish length, the reduced scattering length (RSL), is calculated from each fish as a function of standard length ( $L$; measured in meters), fish aspect relative to the transducer face ( $\theta$; measured in degrees), and acoustic wavelength $(\lambda$; measured in meters) to compare individual components. The acoustic wavelength is a function of the speed of sound in water ( $c$; measured in meters per second) and transmitting frequency $(f$; measured in hertz) (i.e., $\lambda=c / f)$. Full details of the model can be found in Clay and Horne (1994), Jech et al. (1995), or the appendix in Horne and Jech (1999).

Individual fish were modeled over a length range of $300-1,300 \mathrm{~mm}$, an aspect range of $70-110^{\circ}$, and an acoustic frequency range of $12-420 \mathrm{kHz}$. Average and standard deviation backscatter values at $200 \mathrm{kHz}$ were calculated for age- 0 and adult paddlefish, converted to TS $\left(=20 \cdot \log _{10}[\mathrm{RSL}]+\right.$ $20 \cdot \log _{10} L$ ), and plotted to examine the effect of length on predicted backscatter. Field measures of TS were plotted in the same graph for comparison, but separate models were necessary for age- 0 and adult fish because data for intermediate-sized fish were not available and differences in size were too great to model these fish collectively.

Abundance estimates.-The potential use of 
acoustics to estimate paddlefish abundance was explored in two small water bodies where paddlefish could be contained. The first experiment was conducted to determine whether paddlefish could be counted with acoustic surveys; therefore, we stocked a known number of paddlefish in Hebron Pond and compared results of six consecutive surveys. A pond survey was defined as one set of data collected with a side-looking transducer aimed from the pond center toward the bank while we drove the boat in a circular pattern. The sidelooking transducer was mounted $1 \mathrm{~m}$ below the water surface, and data were collected from points 1 to $20 \mathrm{~m}$ from the boat. On October 4, 1999, 21 adult paddlefish (912-1,364 mm SL) were stocked in the pond. Acoustic sampling began $18 \mathrm{~h}$ after fish were stocked. Six pond surveys were conducted, and 15 min elapsed between the end of each survey and the beginning of the next.

The second experiment was conducted in Horseshoe Lake to explore the estimation of paddlefish abundance from counts of large fish, presumably adult paddlefish, as indicated by TS. A survey in Horseshoe Lake was defined as a series of consecutive acoustic transects conducted with either side-looking or down-looking data collections. The population of paddlefish was confined within the lake and sampled with acoustics, and then acoustic abundance estimates were compared to depletion gillnetting estimates. The inlet to Horseshoe Lake was blocked off with a $25-\mathrm{mm}$-mesh net on October 5, 1999, to prevent paddlefish from moving into or out of the lake. Mobile acoustic surveys were conducted during day and night on October 5 with side-looking and down-looking sampling at survey speeds of $2.5 \mathrm{~m} / \mathrm{s}$. The top 2 $\mathrm{m}$ of the water column were sampled by use of side-looking surveys with the transducer mounted $1 \mathrm{~m}$ below the water surface and with the maximum range set to $20 \mathrm{~m}$. Down-looking surveys were used to sample the entire water column from $2 \mathrm{~m}$ below the surface to approximately the bottom, with the transducer mounted $0.5 \mathrm{~m}$ below the water surface and the start range set at $1.5 \mathrm{~m}$. Targets greater than $-29.46 \mathrm{~dB}$ were defined as potential adult paddlefish based upon tethering experiment results. Latitude and longitude were recorded during each survey to provide location of targets.

Tracking TS of multiple consecutive pings was used to identify and count paddlefish targets. BioSonics Analyzer version 3.11 software was used for analysis of down-looking data, and BioSonics VTrack version 0.98 software was used for analysis of side-looking data (BioSonics 1999). Down-looking data were analyzed by selecting individual tracks of fish and outputting echo results to files to provide estimated fish size, location, and depth. Side-looking data were similarly analyzed, but VTrack software was used to output tracked fish due to the larger number of fish in the dataset. VTrack could not be used for down-looking analysis because it is unable to track and exclude bottom echoes.

Counts of adult paddlefish determined from analysis of each survey were examined with a chisquare contingency test (Snedecor and Cochran 1980). This test evaluated the null hypothesis that acoustic counts of paddlefish in side-looking and down-looking surveys were independent of time of sampling (day versus night) at an $\alpha$ value of 0.05 .

Each survey result was used to generate ratio and cluster sampling abundance estimates. We produced ratio estimates by dividing the total number of fish by the total area sampled to estimate density (fish $/ \mathrm{m}^{2}$ ) and variance. To generate cluster estimates, we divided the total number of paddlefish detected by the area sampled for each transect, and then density estimates for survey transects were averaged to produce a mean and variance. Results from both methods were multiplied by the surface area of Horseshoe Lake to estimate total paddlefish abundance.

Gillnetting conducted during October 6-8, 1999 , provided what we defined as a baseline estimate of the Horseshoe Lake paddlefish population for comparison to acoustic-based abundance estimates. Twelve 120-m-long, 4.5-m-deep, 127mm-bar-mesh gill nets were fished for eight 2.5-h periods at fixed locations. Our gear covered all habitat types and depths due to the small size, steep banks, and shallow depth of Horseshoe Lake. Some nets were floated at the surface, whereas others were fished on the bottom. However, nets often spanned the water column from the surface to the bottom and generally extended from the shoreline to one-third or one-half the distance from shore to shore. Fishes caught in each net were identified and measured to the nearest millimeter. The eye-fork length (EF) of paddlefish was measured and converted to SL with the equation SL $=\mathrm{EF}(1.33)+73.71$, which was derived from our data. Total length $(\mathrm{mm})$ was measured for nontarget species. All fishes were marked with a holepunch in the anal fin. Paddlefish were removed from the lake and released in the Ohio River. Nontarget fishes were returned to the lake. The deple- 


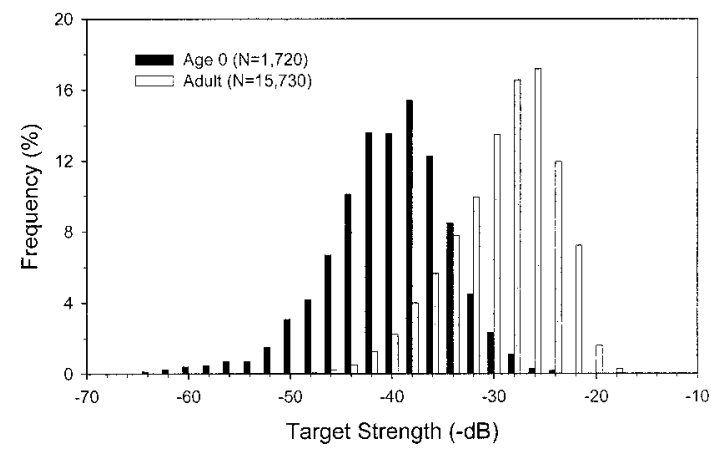

FIGURE 1.-Target strength distribution of measurements of age- 0 and adult paddlefish sampled at $200 \mathrm{kHz}$ $(N=$ number of pings $)$.

tion method was used to estimate the number of paddlefish in Horseshoe Lake (Ricker 1975). Gillnet bycatch indicated the percentage of large fish that might be confused as paddlefish in acoustic surveys.

\section{Results}

\section{Target Strength Measurements}

Target strengths were measured for 24 paddlefish that we categorized as either age 0 or adult. Intermediate-length paddlefish were not available because we could not capture them in the wild or obtain them by other means. Individual echo returns from age-0 fish had a wider TS distribution than adult paddlefish, despite minimal variation in lengths of tethered fish in either size-group. Large variation among individual echo returns resulted in overlap of TS between age- 0 and adult paddlefish based on single pings, particularly between -40 and $-30 \mathrm{~dB}$ (Figure 1). However, distributions of TS were distinctly different between the two length-groups (Figure 1).

The grand mean of TS from individual age- 0 paddlefish was significantly lower than that of adult paddlefish, indicating that the two lengthgroups could be differentiated despite some overlap in TS distributions $(P<0.01, t=19.64$, $\mathrm{df}=$ 22). Mean TS of four age-0 paddlefish (353-406 $\mathrm{mm} \mathrm{SL}$ ) ranged from $-39.48 \mathrm{~dB}$ (upper $\mathrm{SD}=$ -3.41 ) to $-34.18 \mathrm{~dB}$ (upper $\mathrm{SD}=-4.05$ ), with a grand mean of $-37.14 \mathrm{~dB}(\mathrm{SD}=-2.36)$. Mean TS of 20 adult paddlefish $(1,018-1,284 \mathrm{~mm} \mathrm{SL})$ ranged from $-30.87 \mathrm{~dB}$ (upper $\mathrm{SD}=-3.85$ ) to $-23.14 \mathrm{~dB}$ (upper $\mathrm{SD}=-3.46$ ), with a grand mean of $-27.25 \mathrm{~dB}(\mathrm{SD}=-2.21)$.

We assumed that most adult paddlefish would provide TS within one SD of the mean based on tethering experiment results; therefore, we used TS

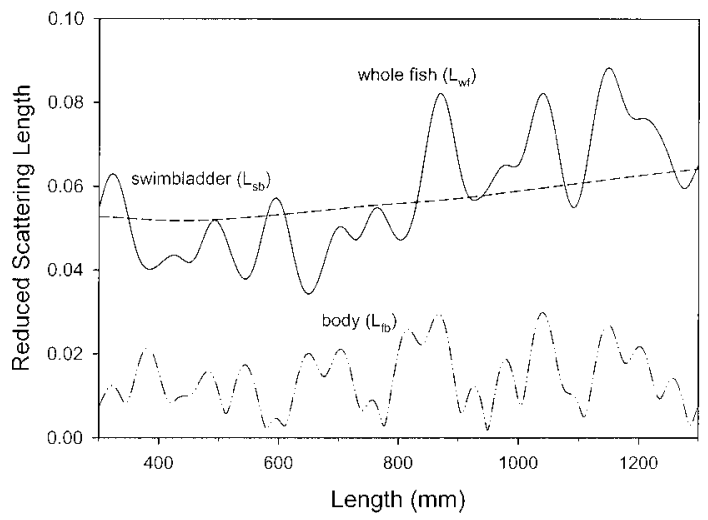

FIGURE 2.-Swim bladder (uniformly dashed line), body (dotted and dashed line), and whole-fish (solid line) components of reduced scattering length in an anatomically based acoustic backscatter model developed from a 346-mm paddlefish. This example represents results for 300-1,300-mm fish.

greater than $-29.46 \mathrm{~dB}(\mathrm{TS}+1 \mathrm{SD})$ to identify targets as adult paddlefish in acoustic surveys. This approach provided a conservative estimate of TS to identify adult paddlefish and to avoid confusing them with age-0 paddlefish or other nontarget species during surveys. Individual TS distributions indicated that $98 \%$ of age- 0 pings were less than $-29.46 \mathrm{~dB}$, whereas $58 \%$ of adult pings were greater than $-29.46 \mathrm{~dB}$. We also used this approach because identification of a large fish for counting was based on tracking TS of multiple consecutive pings rather than the return from a single ping.

\section{Backscatter Models}

Anatomically based acoustic backscatter models of paddlefish were developed for age-0 (336-346 $\mathrm{mm} ; n=3)$ and adult $(894-1,277 \mathrm{~mm} ; n=7)$ fish. Preliminary calculations of the ratio of fish length to acoustic wavelength $(L / \lambda)$ showed that $L / \lambda$ values ranged from $2.69(12 \mathrm{kHz})$ to 96.88 $(420 \mathrm{kHz})$ in age-0 paddlefish and from 7.15 (12 $\mathrm{kHz})$ to $357.56(420 \mathrm{kHz})$ in adult paddlefish. These ratios became particularly large for adult paddlefish sampled with frequencies greater than $70 \mathrm{kHz}$.

Paddlefish had a single, large swim bladder located slightly posterior relative to the entire length of the fish when the rostrum was included. Kirchhoff-ray-mode backscatter models indicated that the swim bladder was the primary source of acoustic backscatter (Figure 2). Figure 2 provides model results developed from a $346-\mathrm{mm}$ paddle- 
fish to indicate how components of a fish body contribute to RSL for $300-1,300-\mathrm{mm}$ paddlefish. This model demonstrates that acoustic scattering by the swim bladder ( $L_{\mathrm{sb}}$; uniformly dashed line) was many times greater than that of the body $\left(L_{\mathrm{fb}}\right.$; dotted and dashed line). When coherent backscatter of the whole fish is assumed, components of returned sound from the swim bladder and body were summed ( $L_{\mathrm{wf}}$; solid line) to indicate the strong influence of the swim bladder on amplitude and of body shape on variability of returned sound.

Backscatter models for individual fish differed conspicuously between age-0 fish and adults. Backscatter amplitude was extremely sensitive to fish tilt in the age-0 and adult models (Figure 3). Sharp peaks in backscatter amplitude at $85-95^{\circ}$ aspects, which aligned the dorsal surface of the swim bladder perpendicular to the transducer (i.e., horizontal), quickly dissipated to low amplitudes when fish tilted head up or head down. This effect was most pronounced in adults. When fish length was held constant along the $L$ to $\lambda$ axis, an increase in acoustic carrier frequency corresponded to a greater $L / \lambda$ value. Backscatter amplitude increased as $L$ increased when carrier frequency was held constant. Backscatter model results from adult fish returned stronger peak signals at all lengths than those derived from age-0 fish. Variation in peaks at fixed aspects reflected areas of constructive and destructive backscatter interference between the swim bladder and fish body. Anatomically based models demonstrated that influences of fish aspect on TS were greatest for large paddlefish, but confirmed that these effects could be reduced at lower $L / \lambda$ values for both length-groups of paddlefish, for example by use of $38-\mathrm{kHz}$ or $70-\mathrm{kHz}$ frequency transducers.

Backscatter model results were compared with field measures at $200 \mathrm{kHz}$ separately for age- 0 and adult paddlefish (Figure 4). Discontinuity of the solid line of Figure 4 occurred because two separate model results were necessary due to the large difference in the two size-groups of fish used to model TS. Two of four measured results from age0 fish were lower than model results, whereas 18 of 20 measured results from adult fish were greater than model results. However, means of measured TS were generally within one SD of model results for both size-groups, and the match between measured and modeled TS was good.

\section{Abundance Estimates}

Acoustic counts in Hebron Pond.-The acoustic counts of paddlefish stocked in Hebron Pond de- clined precipitously after the first of six pond surveys. Although we stocked 21 paddlefish in the pond, we counted 24 paddlefish in the first survey, indicating that some fish were counted more than once, as no other large fish were present. In the second survey, we counted only seven paddlefish, and in the following four surveys we counted between two and five paddlefish. Paddlefish behavior clearly influenced our ability to count adult paddlefish with acoustic surveys in Hebron Pond.

Horseshoe Lake abundance estimates.-Acoustic surveys of Horseshoe Lake identified 13 paddlefish targets during the day and 15 paddlefish targets at night. The numbers of fish counted in side-looking and down-looking surveys were dependant upon time of the survey $\left(P<0.01, \chi^{2}=\right.$ 5.07 , df = 1). We counted four fish in side-looking transects and nine fish in down-looking transects during day surveys, and 11 fish in side-looking transects and four fish in down-looking transects at night. Side-looking surveys sampled 2.14$3.68 \%$ of the lake, and down-looking surveys sampled $0.07-0.12 \%$ of lake. A larger percentage of lake area was sampled with side-looking surveys than down-looking surveys because side-looking surveys could consistently sample a full $20 \mathrm{~m}$ from the boat, whereas area sampled in down-looking surveys depended upon depth. Maximum average beam width was $3.85 \mathrm{~m}$ for side-looking surveys and $1.36 \mathrm{~m}$ (day) and $1.51 \mathrm{~m}$ (night) for downlooking surveys. Differences in beam width of down-looking surveys resulted from minor transect differences. However, mean transect lengths were similar for each acoustic survey method, and the proportion of lake area sampled with sidelooking and down-looking methods was similar during day and night (Table 1).

Whole-lake abundance estimates differed between side-looking and down-looking surveys both day and night, but ratio and cluster estimates produced similar results (Table 1). Day sidelooking estimates $(N \pm 95 \%$ confidence interval) were $187 \pm 182$ fish (ratio estimate) and $252 \pm$ 231 fish (cluster estimate), whereas day downlooking estimates were 12,831 $\pm 8,208$ fish (ratio estimate) and 13,489 \pm 10,531 fish (cluster estimate). Night side-looking estimates were $299 \pm$ 176 fish (ratio estimate) and $313 \pm 121$ fish (cluster estimate), whereas night down-looking estimates were 3,464 $\pm 3,373$ fish (ratio estimate) and $3,556 \pm 2,992$ fish (cluster estimate). Night sidelooking estimates were the most precise, and the coefficient of variation of the mean (100.SE/mean) ranged from $20 \%$ to $50 \%$. 

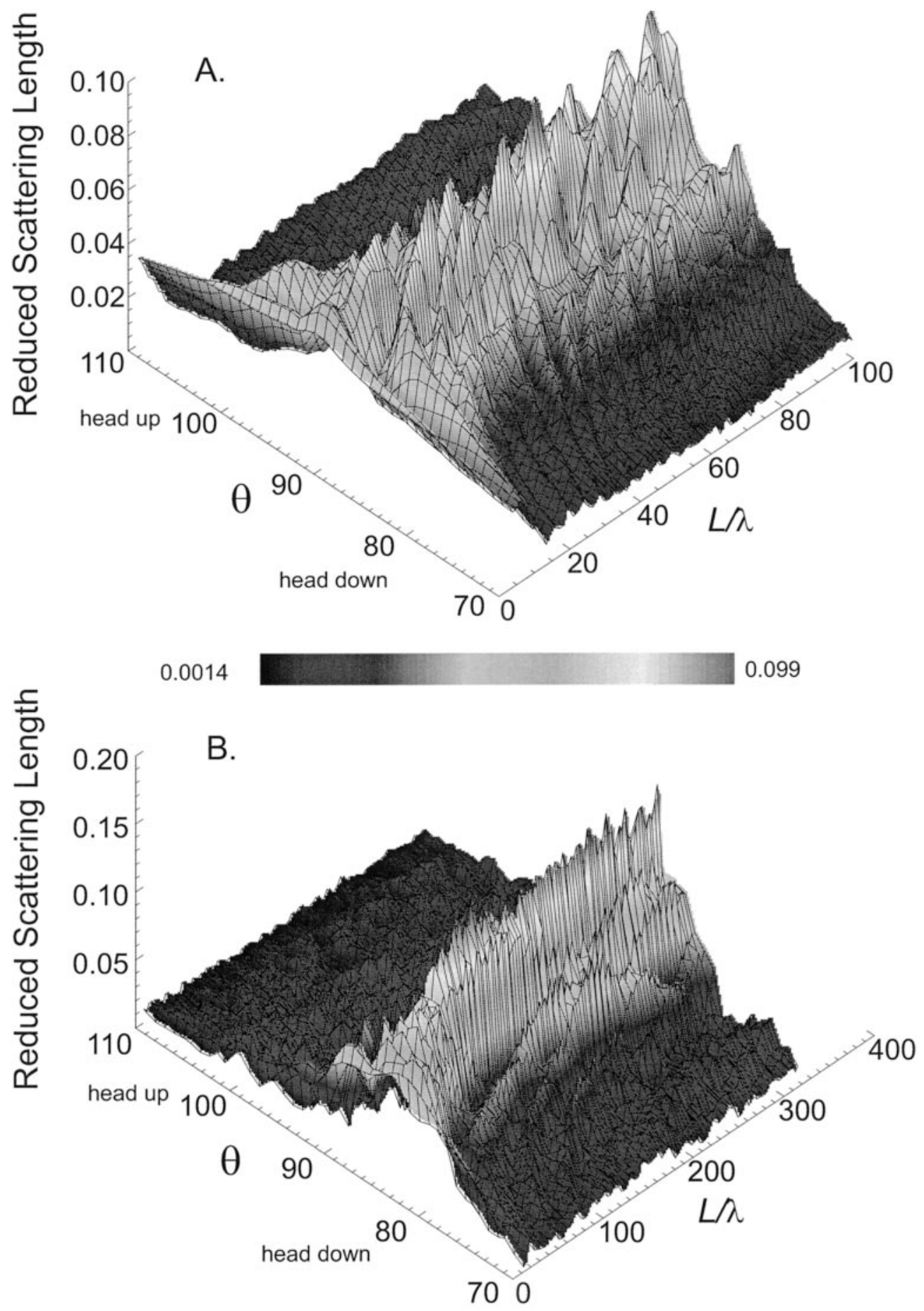

0.00026

0.16

Figure 3.- Predicted reduced scattering length of (A) a 346-mm age-0 paddlefish and (B) a 1,096-mm adult paddlefish plotted as a function of fish aspect $(\theta)$ and the ratio of fish length $(L)$ to acoustic wavelength $(\lambda)$ and modeled over an aspect range of $70-110^{\circ}$ and an acoustic frequency range of $12-420 \mathrm{kHz}$. 


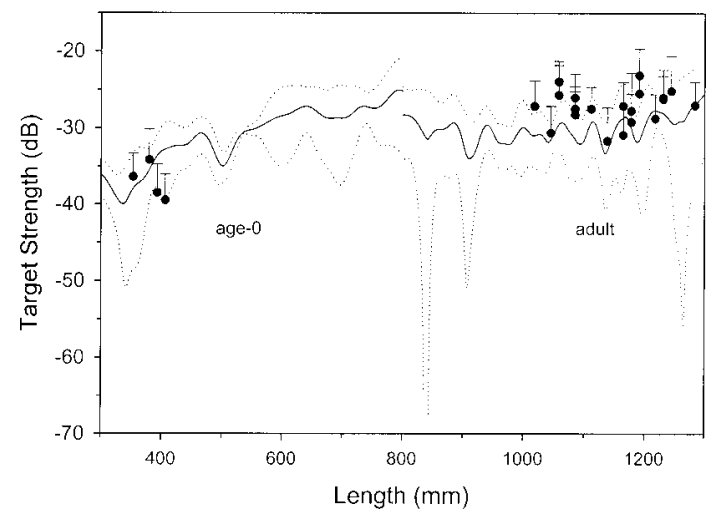

FIGURE 4.- Target strength (solid line) and SDs (dotted lines) of age- 0 and adult paddlefish predicted from anatomically based models, compared with the measured mean target strength (black dots; +1 SD) at $200 \mathrm{kHz}$.

An estimated $130 \pm 55$ paddlefish were in Horseshoe Lake based on depletion gillnetting results used to develop the equation $y=1.075-0.008 x$ $\left(P=0.01, F=12.97, r^{2}=0.68\right)$, where $y$ is gillnet catch per effort and $x$ is cumulative catch. A total of 110 adult paddlefish and 29 nontarget fish, including 11 common carp, 10 bigmouth buffalo, 6 smallmouth buffalo, and 2 black buffalo, were captured in 96 gill-net sets. Lengths of gillnetted paddlefish overlapped with those used for measurement of TS and development of backscatter models, but few of the nontarget species, representing $21 \%$ of the total gill-net catch, overlapped with lengths of paddlefish sampled (Figure 5).

\section{Discussion}

Counting and estimating abundance of large fish with acoustics is contingent upon meaningful TS information. Paddlefish are physostomes, with a large swim bladder and an irregular body shape compared with teleosts, and echo amplitudes from paddlefish are large. We could differentiate age- 0 and adult paddlefish because differences in mean TS were large. Use of acoustic TS to differentiate large adult freshwater fishes from age-0 fish of the same species or from smaller coexisting species should be possible because TS is generally proportional to fish size (Love 1969, 1971, 1977). Age0 and adult fish have been differentiated via TS for a number of smaller species. Burczynski et al. (1987) differentiated age-0 and older age-classes of rainbow smelt Osmerus mordax in Lake Oahe, South Dakota, with a dual-beam, $420-\mathrm{kHz}$ sonar. Parkinson et al. (1994) used a similar sonar to separate kokanee Oncorhynchus nerka into age-0 and age-1-3 groups in Coeur d'Alene Lake, Idaho, although differentiating between ages 1-3 required trawl samples. By use of a $70-\mathrm{kHz}$, split-beam sonar, Warner et al. (2002) identified two or three sizeclasses of alewives Alosa pseudoharengus in surveys conducted in eight inland New York lakes from July through November. However, Buerkle (1987) cautioned against use of TS to differentiate lengthgroups by providing an example of TS reductions associated with increases in fish tilt rather than fish length in Atlantic cod Gadus morhua.

Acoustic backscatter models confirmed that paddlefish TS is a complex function of both biological and equipment factors and that adult paddlefish TS is particularly sensitive to fish tilt, or angle to transducer, and sonar frequency. Similar sensitivity of TS to tilt and sonar frequency might be expected for other large freshwater fishes because models of threadfin shad Dorosoma petenense (Jech et al. 1995) and Atlantic cod (Clay and Horne 1994) identify similar interrelations of these factors. Importance of the paddlefish swim bladder to TS is also consistent with findings that the swim bladder contributes $90-95 \%$ of maximum and average dorsal-aspect acoustic backscatter for three gadoid species (Foote 1980). Paddlefish models identified the importance of large swim bladders to amplitude of acoustic backscatter, and also demonstrated that when paddlefish are tilted either head up or head down relative to the transducer, the returned sound will greatly diminish.

The potential for diminished acoustic backscatter for a given echo is more pronounced as $L / \lambda$ increases, but these concerns can be partially addressed with selection of an appropriate sonar system. Clay and Horne (1994) suggest that sonar frequencies providing $L / \lambda$ between 2 and 10 may be most useful for fish identification, yet in our study, $L / \lambda$ for adult paddlefish was approximately 154. Lower frequencies commonly used in acoustic surveys would have reduced $L / \lambda$ to 92 (120 $\mathrm{kHz}), 54(70 \mathrm{kHz})$, or $29(38 \mathrm{kHz})$. Sonar frequencies of $70 \mathrm{kHz}$ or lower would improve fish identification because the influences of fish length and aspect on acoustic backscatter are reduced. However, the transducer near field also must be considered in selection of any sampling frequency, particularly in shallow habitats such as those we sampled for paddlefish. Near field is the area immediately in front of the transducer face where transducer operation may not be linear, and is a function of transducer frequency and acoustic beam angle. For example, a $200-\mathrm{kHz}, 6^{\circ}$ transducer has a $0.8-\mathrm{m}$ near field, whereas a $38-\mathrm{kHz}, 6^{\circ}$ trans- 
TABLE 1.-Acoustic survey results and estimates of paddlefish abundance in Horseshoe Lake, Ohio, October 1999. Means and $95 \%$ confidence intervals are shown for transect length and abundance. The coefficient of variation of the mean (100.SE/mean) is given in parentheses below each abundance estimate; $N=$ number of survey transects.

\begin{tabular}{|c|c|c|c|c|c|c|c|}
\hline \multirow[b]{2}{*}{ Period } & \multirow[b]{2}{*}{ Survey } & \multirow[b]{2}{*}{$N$} & \multirow{2}{*}{$\begin{array}{l}\text { Transect } \\
\text { length } \\
\text { (m) }\end{array}$} & \multirow[b]{2}{*}{$\begin{array}{l}\% \text { of lake } \\
\text { sampled }\end{array}$} & \multirow{2}{*}{$\begin{array}{l}\text { Number } \\
\text { of fish } \\
\text { counted }\end{array}$} & \multicolumn{2}{|c|}{ Abundance } \\
\hline & & & & & & $\begin{array}{l}\text { Ratio } \\
\text { estimate }\end{array}$ & $\begin{array}{l}\text { Cluster } \\
\text { estimate }\end{array}$ \\
\hline \multirow[t]{2}{*}{ Day } & Side looking & 7 & $44 \pm 13$ & 2.14 & 4 & $\begin{array}{c}187 \pm 182 \\
(50)\end{array}$ & $\begin{array}{c}252 \pm 231 \\
(47)\end{array}$ \\
\hline & Down looking & 6 & $48 \pm 15$ & 0.07 & 9 & $\begin{array}{c}12,831 \pm 8,208 \\
(33)\end{array}$ & $\begin{array}{c}13,489 \pm 10,531 \\
(40)\end{array}$ \\
\hline \multirow[t]{2}{*}{ Night } & Side looking & 11 & $48 \pm 8$ & 3.68 & 11 & $\begin{array}{c}299 \pm 176 \\
(30)\end{array}$ & $\begin{array}{c}313 \pm 121 \\
(20)\end{array}$ \\
\hline & Down looking & 10 & $44 \pm 11$ & 0.12 & 4 & $\begin{array}{c}3,464 \pm 3,373 \\
(50)\end{array}$ & $\begin{array}{c}3,556 \pm 2,992 \\
(43)\end{array}$ \\
\hline
\end{tabular}

ducer has a $4.1-\mathrm{m}$ near field; therefore, a $10^{\circ}$ beam angle would be required to reduce the near field of a $38-\mathrm{kHz}$ transducer to $1.5 \mathrm{~m}$ and maximize sampling efficiency. Smaller beam angles at low frequencies would miss a large portion of habitat in down-looking transects with mean depths of 5$10 \mathrm{~m}$, whereas large beam angles would increase sampling area.

As in other reported results, the measurement of paddlefish TS agreed well with TS predicted from backscatter models. Foote and Traynor (1988) indicated that TS of walleye pollock Theragra chalcogramma measured in situ at $38 \mathrm{kHz}$ compared well to modeled results, but modeled averages were consistently lower than measured averages. Clay and Horne (1994) found a good match between their models of Atlantic cod and measured results from dead, tethered cod reported at $38 \mathrm{kHz}$. Jech et al. (1995) reported that TS of live, tethered threadfin shad compared well with one model based on fish morphology (i.e., body and swim bladder) and two additional models based upon cylinder representations of fish morphology at 120, 200, and $420 \mathrm{kHz}$. Differences we observed between measured and modeled paddlefish TS may have resulted from tethering, anesthesia, or fish handling (MacLennan and Simmonds 1992) or from errors in models.

Pond experiments demonstrated the potential influence of fish behavior on acoustic surveys. Our fist survey of Hebron Pond allowed us to identify 24 large targets when 21 large targets were present, resulting from sampling some fish more than once, whereas subsequent pond surveys failed to locate even half as many. Some high-frequency sounds of $110-140 \mathrm{kHz}$ emitted from stationary transducers create avoidance responses from alewives (Dunning et al. 1992) and blueback herring Alosa aestivalis (Nestler et al. 1992). However, we do not believe that acoustic beam avoidance was an issue in our mobile paddlefish surveys or else we would have observed that response in the first survey. Given our results, we suspect that once we created an initial disturbance by boat operation in Hebron Pond, paddlefish moved to the bottom or center of the pond or swam at aspects that returned weak echoes. Both types of behavior, avoidance or orientation changes in response to an approaching boat, are concerns warranted in acoustic surveys (Olsen et al. 1983). Our results do not let us conclude whether behavior is a significant issue in paddlefish surveys conducted in larger habitats where transects are not replicated during a short time frame.

Differences in acoustic counts of paddlefish between side-looking and down-looking surveys conducted during the day and at night indicated that diurnal movement should be considered in acoustic survey design. During the Horseshoe Lake surveys, paddlefish were more likely to be near the surface at night than during the day. Shallow night movement and seasonal differences in depth selection of paddlefish were observed by Zigler et al. (1999) in an Upper Mississippi River telemetry study. Complete acoustic coverage with both methods appears important. We would have missed most of the fish in the top $2 \mathrm{~m}$ of the water column without side-looking acoustics; these fish represented nearly one-third of large targets counted during the day and nearly three-fourths of large targets counted at night. Light intensity may also be a significant issue during night surveys. Luecke and Wurtsbaugh (1993) found that Bonneville ciscoes Prosopium gemmifer dispersed closer to the bottom during the full moon compared to the new moon in Bear Lake, Utah, creating difficulty in detecting fish during the full moon and reducing acoustic density and biomass estimates by $50 \%$. 

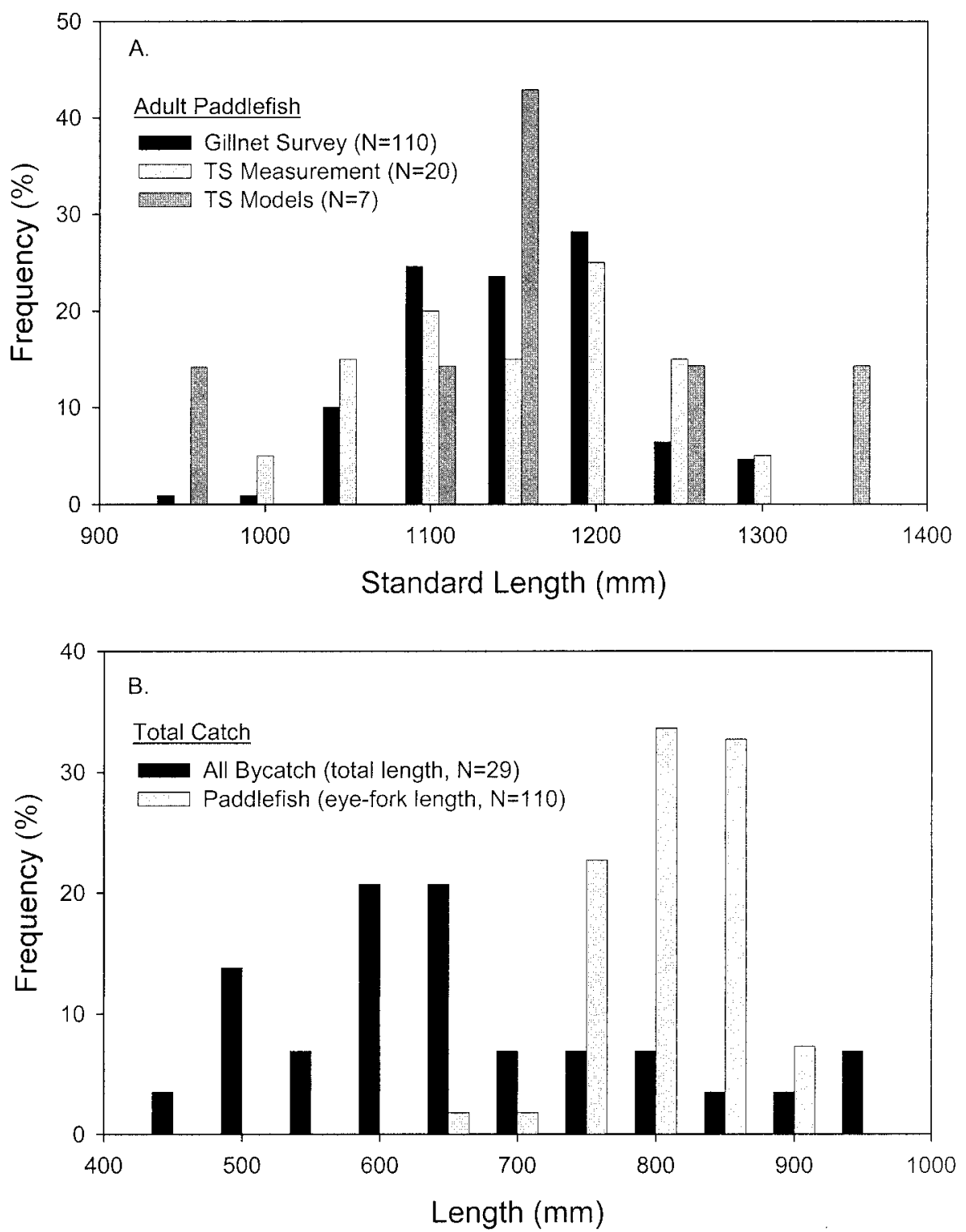

FIGURE 5.-(A) Length frequency distribution of paddlefish sampled with gill nets in Horseshoe Lake, adult paddlefish tethered to estimate target strength, and adult paddlefish measured for anatomically based models and (B) length frequency distribution of adult paddlefish converted back to eye-fork length for comparison with total length of bycatch.

Abundance estimates from acoustic counts of adult paddlefish in Horseshoe Lake were greater or more variable than population estimates derived from depletion gillnetting. These differences could have been related to bycatch, sampling effort, sampling methods, or approaches to analysis. Species composition is an important consideration in acoustic surveys. Yule (2000) found similar densities of salmonids in acoustic surveys and purse- seine hauls in Wyoming lakes and reservoirs, where purse seine bycatch was generally less than $10 \%$. Cryer (1996) reported a good match of 10 acoustic surveys of rainbow trout Oncorhynchus mykiss from acoustic counts in Lake Taupo, New Zealand, with expectations from a range of published empirical models and a recent creel survey. Rainbow trout were the only large pelagic species and could easily be separated by TS from the other 
pelagic species, the New Zealand common smelt Retropinna retropinna, in steep-sided Lake Taupo. Horseshoe Lake gillnetting conservatively indicated that at least one-fifth of acoustic abundance estimates could have been comprised of common carp, bigmouth buffalo, smallmouth buffalo, or black buffalo. Although body sizes of adult paddlefish and bycatch species did not overlap considerably, we do not have information about TS of these nontarget species, and vulnerability of bycatch to our gill nets may have differed from that of paddlefish. If our acoustic abundance results were corrected for bycatch, side-looking surveys would have provided a range of 150-250 adult paddlefish and down-looking surveys would have provided a range of 2,771-10,791 adult paddlefish.

The large discrepancy between down-looking abundance estimates and those from side-looking acoustic surveys and gill-net surveys also suggested that sampling effort was important. Differences in sampling effort were considerable between down-looking and side-looking surveys. Although duration of the surveys was similar, the down-looking acoustic beam was considerably reduced relative to the side-looking beam due to shallow lake depth. The low percentage of area sampled in the down-looking survey would be expected to increase variance (Thorne 1983), but it may also have inflated abundance estimates or the influence of bycatch.

The smaller number of paddlefish counted and their distribution may also have inflated ratio and cluster estimates. Conners and Schwager (2002) have shown that a simple sample mean may have a strong nonnormal distribution when transects are sampled from a spatially clustered population. If the distribution of paddlefish or other large fishes is clustered, then results such as these may violate the standard design assumption that target organisms are evenly distributed in space such that each transect may be considered a random draw from an identical underlying distribution. Although it is possible to deal with clustering through modelbased estimation such as kriging (MacLennan and Simmonds 1992; Petitgas 1993), the very small numbers of fish detected in our surveys constrained the estimation of parameters for these models. Given this problem, down-looking results, in particular, may have been improved by increasing both sampling area and number of transects, and by stratifying sampling design by habitat (Cochran 1977; Jolly and Hampton 1989).

One alternative approach to ratio or cluster sampling estimates is adaptive cluster sampling, a meth- od that incorporates the spatial distribution of fish in the analysis and that is not dependant on the presence of large numbers of fish or on their homogenous distribution (Thompson 1991; Thompson and Seber 1996). Adaptive cluster sampling involves oversampling an area when target organisms are identified in random transects, and then estimating abundance via an analysis that incorporates cluster size and geographic distributions of organism clusters. This method is particularly suited for estimating abundance of organisms found in low abundance but in clustered distributions, and may be useful for surveys of paddlefish or other large fishes. We could not apply this approach post hoc because we did not sample adaptively and did not have enough information to make reasonable assumptions about the shape of clusters.

Acoustic surveys generally require less field effort and little or no fish handling compared with alternative methods, the exact amounts depending upon the level of supplemental sampling required. In Horseshoe Lake, four acoustic surveys required approximately 6 man-hours (calibration, setup, and surveys) compared to 180 man-hours for one depletion gillnetting survey. Within the Mississippi River basin, paddlefish catch rates have been reported at $0.5 \mathrm{fish} / \mathrm{h}$ for gillnetting, $6.5 \mathrm{fish} / \mathrm{h}$ for electrofishing, and from 0.2 to $1.3 \mathrm{fish} / \mathrm{h}$ for snagging with rod and reel (Grady and Conover 1998). None of these methods provided estimates of abundance, but rather general indicators or indexes. In contrast, we estimated that our mobile acoustic surveys conducted at $2.5 \mathrm{~m} / \mathrm{s}$ counted paddlefish, or large fish targets, at a rate of $16.8 \mathrm{fish} / \mathrm{h}$ and did not require handling of fish. Paddlefish injury has been associated with electrofishing (Scarnecchia et al. 1999), and gillnetting and snagging pose other potential sources of injury or mortality, but such concerns do not exist during acoustic surveys. The short time required to conduct acoustic surveys in Horseshoe Lake demonstrated the potential cost savings and greater spatial coverage for sampling large fish compared to effort expended in methods such as gillnetting or electrofishing. Acoustic surveys also provide an alternative to methods of estimating paddlefish abundance, which historically relied on reports of sport or commercial fishery catches (Gengerke 1986).

Our results are the first to indicate the potential of fisheries acoustics to estimate paddlefish abundance, and we recommend use of acoustics for sampling paddlefish and other large freshwater fishes. These findings are significant given the paucity of noninvasive techniques available to sample 
paddlefish and other large fishes and the increasing need to quantify their abundance. Specific recommendations include: (1) use of sonar frequencies of $70 \mathrm{kHz}$ or lower, with the largest acoustic beam angle possible given near-field considerations for habitat sampled; (2) concurrent sampling of fish populations with an alternative method to identify bycatch; and (3) development of survey designs that rigorously consider sampling effort, stratification of habitat, and geographic distribution of target species.

\section{Acknowledgments}

We thank J. Stafford and staff at the Hebron State Fish Hatchery, Ohio Department of Natural Resources (ODNR) for assistance with care, holding, and transportation of paddlefish; S. Mimms, Kentucky State University, for providing paddlefish; and D. Savage for project support through permitting use of his property to conduct the Horseshoe Lake sampling. G. Disterdick and E. Wisner, The Ohio State University Equine and Bovine Veterinary Clinic, provided facilities, advice, and materials for radiographs. A. Mueller, Aquacoustics, Inc., provided assistance with analysis and manuscript review. T. Stefanavage and L. Lehman of the Indiana Department of Natural Resources and C. Goings, R. Hoover, J. Mion, J. Navarro, and $\mathrm{S}$. Xenakis of the ODNR provided assistance with field sampling. R. Hale and D. Degan acknowledge funding provided by the Ohio Wildlife Diversity Fund and the Ohio River Trust Fund, and J. Horne acknowledges funding provided by the U.S. Office of Naval Research.

\section{References}

Anderson, W. G., R. S. McKinley, and M. Colavecchia. 1997. The use of clove oil as an anesthetic for rainbow trout and its effects on swimming performance. North American Journal of Fisheries Management 17:301-307.

Beauchamp, D. A., C. Luecke, W. A. Wurtsbaugh, H. G. Gross, P. E. Budy, S. Spaulding, R. Dillenger, and C. P. Gubala. 1997. Hydroacoustic assessment of abundance and diel distribution of sockeye salmon and kokanee in the Sawtooth Valley lakes, Idaho. North American Journal of Fisheries Management 17:253-267.

BioSonics. 1999. Guide to using DT series hardware and software, manual version 4.0. BioSonics, Seattle.

Brandt, S. B. 1996. Acoustic assessment of fish abundance and distribution. Page 385-432 in B. R. Murphy and D. W. Willis, editors. Fisheries techniques, 2nd edition. American Fisheries Society, Bethesda, Maryland.

Brandt, S. B., D. M. Mason, E. V. Patrick, R. L. Argyle,
L. Wells, and P. A. Unger. 1991. Acoustic measures of the abundance and size of pelagic planktivores in Lake Michigan. Canadian Journal of Fisheries and Aquatic Sciences 48:894-908.

Buerkle, U. 1987. Estimation of fish length from acoustic target strength. Canadian Journal of Fisheries and Aquatic Sciences 44:1782-1785.

Burczynski, J. J., P. H. Michaletz, and G. M. Marrone. 1987. Hydroacoustic assessment of the abundance and distribution of rainbow smelt in Lake Oahe. North American Journal of Fisheries Management 7:106-116.

Clay, C. S., and J. K. Horne. 1994. Acoustic models of fish, the Atlantic cod (Gadus morhua). Journal of the Acoustical Society of America 96:1661-1668.

Cochran, W. G. 1977. Sampling techniques. Wiley, New York.

Conners, M. E., and S. J. Schwager. 2002. Use of adaptive cluster sampling for hydroacoustic surveys. ICES Journal of Marine Science 59:1314-1325.

Cryer, M. 1996. A hydroacoustic assessment of a rainbow trout (Oncorhynchus mykiss) population in a deep oligotrophic lake. Pages 196-205 in I. G. Cowx, editor. Stock assessment in inland fisheries. Blackwell Scientific Publications, Cambridge, Massachusetts.

Degan, D. J., and W. Wilson. 1995. Comparison of four hydroacoustic frequencies for sampling pelagic fish populations in Lake Texoma. North American Journal of Fisheries Management 15:924-932.

Dunning, D. J., Q. E. Ross, P. Geoghegan, J. J. Reichle, J. K. Menezes, and J. K. Watson. 1992. Alewives avoid high-frequency sound. North American Journal of Fisheries Management 12:407-416.

Fleischer, G. W., R. L. Argyle, and G. L. Curtis. 1997. In situ relations of target strength to fish size for Great Lakes pelagic planktivores. Transactions of the American Fisheries Society 126:786-794.

Foote, K. G. 1980. Importance of the swim bladder in acoustic scattering by fish: a comparison of gadoid and mackerel target strengths. Journal of the Acoustical Society of America 67:2084-2089.

Foote, K. G. 1987. Fish target strength for use in echo integrator surveys. Journal of the Acoustical Society of America 82:981-987.

Foote, K. G., and D. N. MacLennan. 1984. Comparison of copper and tungsten carbide spheres. Journal of the Acoustical Society of America 75:612-616.

Foote, K. G., and J. J. Traynor. 1988. Comparison of walleye pollock target strength estimates determined from in situ measurements and calculations based on swim bladder form. Journal of the Acoustical Society of America 83:9-17.

Gengerke, T. W. 1986. Distribution and abundance of paddlefish in the United States. Pages 22-35 in J. G. Dillard, L. K. Graham, and T. R. Russell editors. The paddlefish: status, management and propagation. American Fisheries Society, North Central Division, Special Publication 7, Bethesda, Maryland.

Grady, J. M., and G. A. Conover. 1998. Mississippi River basin paddlefish research, coded-wire tagging project. Mississippi Interstate Cooperative Re- 
source Association, Annual Report 1997, Columbia, Missouri.

Henley, D., L. Franklin, S. Hale, C. O'Bara, and T. Stefanavage. 2001. Paddlefish assessment in the Ohio River sub-basin: current status and strategic plan for management. Ohio River Fisheries Management, Team Report ORFMT0101, Columbus.

Horne, J. K., and C. S. Clay. 1998. Sonar systems and aquatic organisms: matching equipment and model parameters. Canadian Journal of Fisheries and Aquatic Sciences 55:1296-1306.

Horne, J. K., and J. M. Jech. 1999. Multi-frequency estimates of fish abundance: constraints of rather high frequencies. ICES Journal of Marine Science 56:184-199.

Jech, J. M., D. M. Schael, D. M. Schael, and C. S. Clay, 1995. Application of three sound scattering models to threadfin shad (Dorosoma petenense). Journal of the Acoustical Society of America 98:2262-2269.

Jennings, C. A., and S. J. Zigler. 2000. Ecology and biology of paddlefish in North America: historical perspectives, management approaches, and research priorities. Reviews in Fish Biology and Fisheries 10:167-181.

Jolly, G. M., and I. Hampton. 1989. A stratified random transect design for acoustic surveys of fish stocks. Canadian Journal of Fisheries and Aquatic Sciences 47:1282-1291.

Love, R. H. 1969. Maximum side aspect target strength of an individual fish. Journal of the Acoustical Society of America 46:746-752.

Love, R. H. 1971. Dorsal-aspect target strength of an individual fish. Journal of the Acoustical Society of America 49:816-823.

Love, R. H. 1977. Target strength of an individual fish at any aspect. Journal of the Acoustical Society of America 62:1397-1403.

Luecke, C., and W. A. Wurtsbaugh. 1993. Effects of moonlight and daylight on hydroacoustic estimates of pelagic fish abundance. Transactions of the American Fisheries Society 122:112-120.

MacLennan, D. N., and E. J. Simmonds. 1992. Fisheries acoustics. Chapman and Hall, New York.

Medwin, H., and S. S. Clay. 1997. Fundamentals of acoustical oceanography. Academic Press, New York.

Mulligan, T. J., and R. Kieser. 1986. Comparison of acoustic population estimates of salmon in a lake with a weir count. Canadian Journal of Fisheries and Aquatic Sciences 43:1373-1385.

Nestler, J. M., G. R. Ploskey, and J. Pickens. 1992. Response of blueback herring to high-frequency sound and implications for reducing entrainment at hydropower dams. North American Journal of Fisheries Management 12:667-683.

Olsen, K. 1977. Orientation measurements of the cod in Lofoten obtained from underwater photographs and their relation to target strength. ICES CM/B: 25 .

Olsen, K., J. Angell, F. Pettersen, and A. Lovik. 1983. Observed fish reactions to a surveying vessel with special references to herring, cod, capelin and polar cod. FAO (Food and Agriculture Organization of the United Nations) Fisheries Reports 300:131-138.

Parkinson, E. A., B. E. Rieman, and L. G. Rudstam. 1994. Comparison of acoustic and trawl methods for estimating density and age composition of kokanee. Transactions of the American Fisheries Society 123:841-854.

Petitgas, P. 1993. Geostatistics for fish stock assessments: a review and an acoustic application. ICES Journal of Marine Science 50:285-298.

Ricker, W. E. 1975. Computation and interpretation of biological statistics of fish populations. Bulletin of the Fisheries Research Board Canada 191.

Runstrom, A. L., B. Vondracek, and C. A. Jennings. 2001. Population statistics for paddlefish in the Wisconsin River. Transactions of the American Fisheries Society 130:546-556.

Scarnecchia, D. L., P. A. Stewart, L. F. Tyckman, G. Van Eeckhout, B. C. Reed, and L. K. Graham. 1999. Caution on the use of electrofishing for paddlefish. Intermountain Journal of Science 5:35-38.

Schael, D. M., J. A. Rice, and D. J. Degan. 1995. Spatial and temporal distribution of threadfin shad in a southeastern reservoir. Transactions of the American Fisheries Society 124:804-812.

Snedecor, G. W., and W. G. Cochran. 1980. Statistical methods. Iowa State University Press, Ames.

Thompson, S. K. 1991. Adaptive cluster sampling: designs with primary and secondary unit. Biometrics 47:1103-1115.

Thompson, S. K., and G. A. F. Seber. 1996. Adaptive sampling. Wiley, New York.

Thorne, R. E. 1983. Application of hydroacoustic assessment techniques to three lakes with contrasting fish distributions. FAO (Food and Agriculture Organization of the United Nations) Fisheries Reports 300:269-277.

Warner, D. M., L. G. Rudstam, and R. A. Klumb. 2002. In situ target strength of alewives in freshwater. 2002. Transactions of the American Fisheries Society 131:212-223.

Yule, D. L. 2000. Comparison of horizontal acoustic and purse-seine estimates of salmonid densities and sizes in eleven Wyoming waters. North American Journal of Fisheries Management 20:759-775.

Zigler, S. J., M. R. Dewey, and B. C. Knights. 1999. Diel movement and habitat use by paddlefish in Navigational Pool 8 of the Upper Mississippi River. North American Journal of Fisheries Management 19:180-187. 